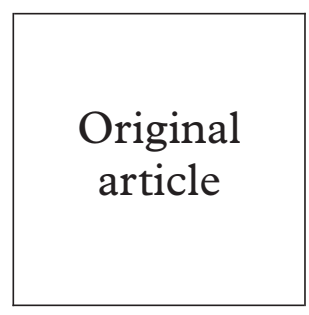

\title{
Demographic and behavioural profile of adults infected with chlamydia: a case-control study
}

\author{
K W Radcliffe, S Ahmad, G Gilleran, J D C Ross
}

Objectives: To determine which demographic and behavioural parameters are independently associated with chlamydial infection in adults.

Methods: Subjects were recruited prospectively from male and female attendees at a large clinic for sexually transmitted infections (STI). All subjects were tested for chlamydia and gonorrhoea and asked to complete a questionnaire addressing demography, sexual and non-sexual (including drug taking) behaviour, and history of STI. Cases were those attending with a new clinical episode and found to be infected with chlamydia, but who did not have gonorrhoea. A control group was selected randomly from those found to be negative on screening for both infections.

Results: 986 cases and 1212 controls were recruited over one calendar year. The following were found to be independent risk factors for chlamydial infection on multivariate analysis (odds ratios with $95 \%$ confidence intervals in parentheses): being unmarried (1.8; 1.1-3.1); black Caribbean ethnicity $(2 ; 1.5-2.7)$. Increasing age, fewer partners, and higher reported use of condoms were associated with a lower risk of infection.

Conclusion: Black Caribbeans are at increased risk from chlamydia after controlling for sexual behaviour and socioeconomic status. Future research should seek an explanation elsewhere-for example, in terms of differences in sexual mixing or effectiveness of healthcare interventions. (Sex Transm Inf 2001;77:265-270)

Keywords: chlamydia; epidemiology; sexual behaviour

\section{Introduction}

Genital infection with Chlamydia trachomatis is an important sexually transmitted infection (STI) which can result in pelvic infection with resultant chronic pelvic pain, tubal infertility and increased risk of ectopic pregnancy; sexually acquired reactive arthritis; epididymoorchitis; conjunctivitis and bronchopneumonia in babies born to infected mothers. ${ }^{1}$

The identification of risk factors significantly associated with genital chlamydial infection may aid in the understanding of the transmission dynamics of this STI and also help to develop interventions targeted at those most at risk. Various studies conducted in STI clinics as well as in general practice in the United Kingdom have shown that a number of demographic factors are associated with increased risk of infection with chlamydia, including female sex, ${ }^{23}$ young adult age, ${ }^{4}$ particularly teenage girls, ${ }^{256}$ and black ethnic origin. ${ }^{45} 7$ Behavioural risk factors include those directly describing aspects of sexual behaviour, and others which, although not directly related to sexual behaviour, may represent surrogate markers of high risk sexual behaviour, such as selection of high risk partners. Direct sexual behaviour risk factors include an increased number of sexual partners ${ }^{4-6}$ and non-use of barrier methods of contraception, such as condoms. ${ }^{8}$ Other risk factors for chlamydia have been demonstrated only in Western countries other than the United Kingdom. These include new sexual partners (United States ${ }^{9}$ ); heterosexual orientation (Australia, ${ }^{10}$ Netherlands, ${ }^{11}$ and Canada ${ }^{12}$ ); smoking crack cocaine (United States $\left.^{13}\right)$; and cigarette smoking $\left(\right.$ Sweden $\left.^{14}\right)$.
Additional risk factors have been shown to be associated with other STI but few data exist with respect to chlamydia-increased alcohol consumption and gonorrhoea in Yugoslavia, ${ }^{15}$ and with STI in general in the United States, ${ }^{16}$ previous gonorrhoea or other STI with gonorrhoea in the United Kingdom, ${ }^{17}$ Netherlands, ${ }^{11}$ and the United States. ${ }^{18}$

To our knowledge only one study has reported on risk factors associated with chlamydial infection from a UK centre other than in London, and this was a retrospective study which included no behavioural data. ${ }^{19}$

We therefore undertook a study to investigate which demographic and behavioural risk factors are associated with chlamydial infection among attendees at a large STI clinic in the centre of Birmingham, United Kingdom (population approximately one million).

\section{Methods}

Ethical approval to conduct the study was obtained from the local research ethics committee.

All male and female patients attending the Whittall Street Clinic in Birmingham during the calendar year 14 June 1997 to 13 June 1998 inclusive were eligible to take part in the study if they presented as a new clinical episode and accepted screening for gonococcal and chlamydial infection. Testing for Chlamydia trachomatis was done using ligase chain reaction $\left(\mathrm{LC}_{\mathrm{x}}\right.$, Abbott) on a urethral swab or urine sample in males, and on a cervical swab in females. Testing for Neisseria gonorrhoeae was done by plating swabs directly onto selective culture media: swabs were routinely taken from the
Accepted for publication 22 May 2001 
urethra in male patients and from both the urethra and the cervix in female patients. Pharyngeal and rectal cultures were also obtained if indicated by the sexual history.

Cases were defined as subjects found to be infected with chlamydia but not with $N$ gonorrhoeae. A similar number of controls were selected, using random number tables, from those patients found to be free of both infections.

All eligible patients were given a structured questionnaire on arrival at the clinic reception, which they were asked to complete on their own and return before leaving. The questionnaire included questions on:

- demographic attributes-age, sex, marital status, self identified ethnic group, and occupational classification (as a surrogate marker of socioeconomic status)

- sexual behaviour-number of self defined regular and casual partners in the preceding year, orientation, use of condoms, number of lifetime foreign partners

- recent use of tobacco, alcohol, and illicit drugs

- self reported previous diagnoses of gonorrhoea and chlamydia.

The data from the questionnaires were entered into an Access 97 database (Microsoft, UK) before transfer to sPSS (v.10, SPSS Inc) for analysis. A univariate comparison of patients with chlamydia infection and control patients was performed using $\chi^{2}$ test. Variables with a significance level less than 0.1 on univariate analysis were entered into a multivariate logistic regression model using a forward conditional (likelihood ratio) method.

A power analysis (EPI-INFO v, 5.01a, CDC, Atlanta, GA, USA) suggested that to detect an odds ratio of 1.5 for a variable with a prevalence of $20 \%$ (power $80 \%$, confidence level $95 \%$ ) would require a sample size of 1124 (562 in each group). To allow for missing data within the study groups a recruitment target of 2000 was set.

\section{Results}

A total of 986 patients with chlamydia and 1212 control patients were entered into the study. This represents a recruitment rate of $83 \%$ of the 1181 chlamydia cases seen over the study period. The characteristics of the study population and completeness of the data set are shown in table 1. On univariate analysis (table 2) all the variables were found to be significantly associated with chlamydial infection except having a history of gonorrhoea or chlamydia. Only one variable on univariate analysis had a significance level greater than 0.1 (history of chlamydial infection) and this was excluded from the multivariate analysis. A large proportion of patients with no casual partners had not replied to the question about condom use in this situation and this variable was therefore also excluded from the multivariate analysis.

Data from 1371 subjects ( 526 cases and 845 controls) who had a complete data set were entered into a multivariate logistic progression
Table 1 Characteristics of the study population

\begin{tabular}{|c|c|c|}
\hline Variable & Male & Female \\
\hline \multicolumn{3}{|l|}{ Age } \\
\hline Under 20 & $88(8 \%)$ & $253(23 \%)$ \\
\hline $20-24$ & $261(24 \%)$ & $332(30 \%)$ \\
\hline $25-30$ & $316(29 \%)$ & $258(23 \%)$ \\
\hline Over 30 & $419(39 \%)$ & $271(24 \%)$ \\
\hline \multicolumn{3}{|l|}{ Marital status } \\
\hline Single & $910(84 \%)$ & $944(85 \%)$ \\
\hline Married & $103(10 \%)$ & $85(8 \%)$ \\
\hline Other ${ }^{\star}$ & $57(5 \%)$ & $68(6 \%)$ \\
\hline No reply & $14(1 \%)$ & $17(2 \%)$ \\
\hline \multicolumn{3}{|l|}{ Ethnic group } \\
\hline White & $589(54 \%)$ & $659(59 \%)$ \\
\hline Black Caribbean & $367(34 \%)$ & $295(26 \%)$ \\
\hline Other & $113(10 \%)$ & $131(12 \%)$ \\
\hline No reply & $15(1 \%)$ & $29(3 \%)$ \\
\hline \multicolumn{3}{|c|}{ Total no of partners (past year) } \\
\hline None & $67(6 \%)$ & $21(2 \%)$ \\
\hline 1 & $194(18 \%)$ & $423(38 \%)$ \\
\hline 2 & $185(17 \%)$ & $236(22 \%)$ \\
\hline 3 or more & $380(35 \%)$ & $242(22 \%)$ \\
\hline No reply & $258(24 \%)$ & $192(18 \%)$ \\
\hline \multicolumn{3}{|c|}{ No of casual partners (past year) } \\
\hline None & $349(32 \%)$ & $646(58 \%)$ \\
\hline 1 & $215(20 \%)$ & $162(14 \%)$ \\
\hline 2 or more & $237(22 \%)$ & $88(8 \%)$ \\
\hline No reply & $283(26 \%)$ & $218(20 \%)$ \\
\hline \multicolumn{3}{|c|}{ Condom use with all partners } \\
\hline Never & $187(17 \%)$ & $239(22 \%)$ \\
\hline Sometimes & $454(42 \%)$ & $563(50 \%)$ \\
\hline Always & $103(10 \%)$ & $90(8 \%)$ \\
\hline No reply & $340(31 \%)$ & $222(20 \%)$ \\
\hline \multicolumn{3}{|c|}{ Condom use with casual partners } \\
\hline Never & $151(14 \%)$ & $95(8 \%)$ \\
\hline Sometimes & $160(15 \%)$ & $69(6 \%)$ \\
\hline Always & $170(16 \%)$ & $131(12 \%)$ \\
\hline No reply & $603(56 \%)$ & $819(74 \%)$ \\
\hline \multicolumn{3}{|c|}{ History of gonorrhoea } \\
\hline No & $805(74 \%)$ & $802(72 \%)$ \\
\hline Yes & $117(11 \%)$ & $84(8 \%)$ \\
\hline No reply & $162(15 \%)$ & $228(20 \%)$ \\
\hline \multicolumn{3}{|l|}{ History of chlamydia } \\
\hline No & $802(74 \%)$ & $740(66 \%)$ \\
\hline Yes & $118(11 \%)$ & $154(14 \%)$ \\
\hline No reply & $164(15 \%)$ & $220(20 \%)$ \\
\hline \multicolumn{3}{|c|}{ History of foreign partner } \\
\hline No & $831(77 \%)$ & $781(70 \%)$ \\
\hline Yes & $214(20 \%)$ & $226(20 \%)$ \\
\hline No reply & $39(4 \%)$ & $107(10 \%$ \\
\hline \multicolumn{3}{|c|}{ No of same sex partners } \\
\hline None & $758(70 \%)$ & $872(78 \%)$ \\
\hline 1 or more & $68(6 \%)$ & $15(1 \%)$ \\
\hline No reply & $258(24 \%)$ & $227(20 \%)$ \\
\hline Alcohol & & \\
\hline None & $347(32 \%)$ & $344(31 \%)$ \\
\hline $1-5$ units/week & $216(20 \%)$ & $425(38 \%)$ \\
\hline$>5$ units/week & $505(47 \%)$ & $326(29 \%)$ \\
\hline No reply & $16(2 \%)$ & $19(2 \%)$ \\
\hline Smoking & & \\
\hline None & $250(24 \%)$ & $200(18 \%)$ \\
\hline $1-5 /$ day & $464(44 \%)$ & $537(49 \%)$ \\
\hline Over 5/day & $349(33 \%)$ & $364(33 \%)$ \\
\hline No reply & $21(2 \%)$ & $13(1 \%)$ \\
\hline Illicit drug use in pa & & \\
\hline No & $489(45 \%)$ & $648(58 \%)$ \\
\hline Yes & $345(32 \%)$ & $268(24 \%)$ \\
\hline No reply & $250(23 \%)$ & $198(18 \%)$ \\
\hline Occupational group & & \\
\hline Homemaker & $0(0 \%)$ & $108(10 \%)$ \\
\hline Student & $118(11 \%)$ & $232(21 \%)$ \\
\hline Unemployed & $188(17 \%)$ & $121(11 \%)$ \\
\hline Working & $512(47 \%)$ & $439(39 \%)$ \\
\hline No reply & $266(24 \%)$ & $214(19 \%)$ \\
\hline
\end{tabular}

$\star$ Divorced, separated, living together, widowed.

model. Seven variables were found to be significantly associated with chlamydial infection (table 3):

- Male sex was associated with an increased risk of infection

- Age over 20 was associated with a lower risk of infection

- Having fewer partners was associated with a lower risk of infection

- Always using condoms was associated with a lower risk of infection 
Table 2 Univariate analysis of demographic and behavioural factors with chlamydial infection

\begin{tabular}{|c|c|c|c|}
\hline Variable & Chlamydia & Controls & $\chi^{2} p$ value \\
\hline \multicolumn{4}{|l|}{ Sex } \\
\hline Female & $471(48 \%)$ & $643(53 \%)$ & \multirow[t]{2}{*}{0.014} \\
\hline Male & $515(52 \%)$ & $569(47 \%)$ & \\
\hline \multicolumn{4}{|l|}{ Age } \\
\hline Under 20 & $214(22 \%)$ & $127(10 \%)$ & \multirow[t]{4}{*}{$<0.001$} \\
\hline $20-24$ & $279(28 \%)$ & $314(26 \%)$ & \\
\hline $25-30$ & $260(26 \%)$ & $314(26 \%)$ & \\
\hline Over 30 & $233(24 \%)$ & $457(38 \%)$ & \\
\hline \multicolumn{4}{|l|}{ Marital status } \\
\hline Single & $895(91 \%)$ & $959(79 \%)$ & \multirow[t]{3}{*}{$<0.001$} \\
\hline Married & $48(5 \%)$ & $140(12 \%)$ & \\
\hline Other ${ }^{\star}$ & $33(3 \%)$ & $92(8 \%)$ & \\
\hline \multicolumn{4}{|l|}{ Ethnic group } \\
\hline White & $472(48 \%)$ & $776(64 \%)$ & \multirow[t]{3}{*}{$<0.001$} \\
\hline Black Caribbean & $397(40 \%)$ & $265(22 \%)$ & \\
\hline Other & $102(10 \%)$ & $142(12 \%)$ & \\
\hline \multicolumn{4}{|c|}{ Total no of partners (past year) } \\
\hline None & $13(2 \%)$ & $75(7 \%)$ & \multirow[t]{4}{*}{$<0.001$} \\
\hline 1 & $172(27 \%)$ & $445(40 \%)$ & \\
\hline 2 & $149(23 \%)$ & $272(25 \%)$ & \\
\hline 3 or more & $308(48 \%)$ & $314(28 \%)$ & \\
\hline \multicolumn{4}{|c|}{ No of casual partners (past year) } \\
\hline None & $317(51 \%)$ & $678(63 \%)$ & \multirow[t]{3}{*}{$<0.001$} \\
\hline 1 & $143(23 \%)$ & $234(22 \%)$ & \\
\hline 2 or more & $166(27 \%)$ & $159(15 \%)$ & \\
\hline \multicolumn{4}{|c|}{ Condom use with all partners } \\
\hline Never & $149(24 \%)$ & $277(27 \%)$ & \multirow[t]{3}{*}{0.002} \\
\hline Sometimes & $415(67 \%)$ & $602(59 \%)$ & \\
\hline Always & $55(9 \%)$ & $138(14 \%)$ & \\
\hline \multicolumn{4}{|c|}{ Condom use with casual partners } \\
\hline Never & $97(29 \%)$ & $149(34 \%)$ & \multirow[t]{3}{*}{0.039} \\
\hline Sometimes & $115(34 \%)$ & $114(26 \%)$ & \\
\hline Always & $124(37 \%)$ & $177(40 \%)$ & \\
\hline History of gonorrho & & & \\
\hline No & $603(87 \%)$ & $1004(90 \%)$ & 0.085 \\
\hline Yes & $88(12 \%)$ & $113(10 \%)$ & \\
\hline History of chlamydi & & & \\
\hline Yes & $115(17 \%)$ & $157(14 \%)$ & 0.12 \\
\hline No & $575(83 \%)$ & $967(86 \%)$ & \\
\hline History of foreign $\mathrm{p}$ & rtner & & \\
\hline No & $770(84 \%)$ & $842(74 \%)$ & $<0.001$ \\
\hline Yes & $149(16 \%)$ & $291(26 \%)$ & \\
\hline No of same sex part & hers & & \\
\hline None & $621(98 \%)$ & $1009(93 \%)$ & $<0.001$ \\
\hline 1 or more & $11(2 \%)$ & $72(7 \%)$ & \\
\hline Alcohol & & & \\
\hline None & $439(45 \%)$ & $252(21 \%)$ & $<0.001$ \\
\hline $1-5$ units/week & $233(24 \%)$ & $408(34 \%)$ & \\
\hline$>5$ units/week & $302(31 \%)$ & $529(44 \%)$ & \\
\hline Smoking & & & \\
\hline None & $358(37 \%)$ & $92(8 \%)$ & $<0.001$ \\
\hline $1-5 /$ day & $330(34 \%)$ & $671(56 \%)$ & \\
\hline Over 5/day & $289(30 \%)$ & $424(36 \%)$ & \\
\hline Illicit drug use in pa & t year & & \\
\hline No & $359(56 \%)$ & $778(70 \%)$ & $<0.001$ \\
\hline Yes & $284(44 \%)$ & $329(30 \%)$ & \\
\hline Occupational group & & & \\
\hline Homemaker & $42(7 \%)$ & $66(6 \%)$ & 0.012 \\
\hline Student & $143(23 \%)$ & $207(19 \%)$ & \\
\hline Unemployed & $130(20 \%)$ & $179(16 \%)$ & \\
\hline Working & $318(50 \%)$ & $633(58 \%)$ & \\
\hline
\end{tabular}

${ }^{\star}$ Divorced, separated, living together, widowed.

- Being single was associated with an increased risk of infection

- Black Caribbean ethnicity was associated with an increased risk of infection

- Smoking less than five cigarettes per day was associated with a reduced risk of infection compared with high smoking rates, but nonsmokers also had an increased risk of infection.

To investigate potential interactions with sex, age, and ethnicity separate logistic regression analyses were performed on the following subgroups-men, women, age under 25, age 25 and over, black Caribbean ethnicity, white ethnicity (tables 4-6). In women there was an association with infection in those classified as homemakers compared with those unemployed or working. Condom use and marital status were not associated with infection in this
Table 3 Multivariate logistic regression analysis of variables associated with chlamydia infection *

\begin{tabular}{|c|c|}
\hline Variable & Odds ratio $(95 \% C I)$ \\
\hline \multicolumn{2}{|l|}{ Sex } \\
\hline Male & $1.3(1.02-1.7)$ \\
\hline \multicolumn{2}{|l|}{ Age group } \\
\hline Under 20 & 1 \\
\hline $20-24$ & $0.4(0.3-0.6)$ \\
\hline $25-30$ & $0.4(0.3-0.6)$ \\
\hline Over 30 & $0.2(0.2-0.4)$ \\
\hline \multicolumn{2}{|c|}{ Total number of partners } \\
\hline 0 & $0.1(0.02-1.05)$ \\
\hline 1 & $0.4(0.3-0.6)$ \\
\hline 2 & $0.7(0.5-0.9)$ \\
\hline Over 2 & 1 \\
\hline \multicolumn{2}{|c|}{ Condom use with all partners } \\
\hline Never & 1 \\
\hline Always & $0.4(0.3-0.7)$ \\
\hline Sometimes/often & $0.8(0.6-1.1)$ \\
\hline \multicolumn{2}{|l|}{ Smoking } \\
\hline None & $17 \quad(1.3-133)$ \\
\hline $1-5 /$ day & $0.7(0.6-0.9)$ \\
\hline Over $5 /$ day & 1 \\
\hline \multicolumn{2}{|l|}{ Marital status } \\
\hline Single & $1.8(1.1-3.1)$ \\
\hline Married & \\
\hline Other & $0.7(0.3-1.6)$ \\
\hline \multicolumn{2}{|l|}{ Ethnic group } \\
\hline White & \\
\hline Black Caribbean & $2 \quad(1.5-2.7)$ \\
\hline Other & $1.2(0.9-1.9)$ \\
\hline
\end{tabular}

*Variables in the model: sex, age, marital status, ethnic group, total number of partners, condom use with partners, history of gonorrhoea, history of foreign partner, number of same sex partners, alcohol, history of illicit drug use, occupational group. †Divorced, separated, living together, widowed.

group. For male patients illicit drug use was associated with an increased risk of infection, but age was no longer a significant variable.

Those under the age of 25 (table 5) no longer had an association between marital status or sex with infection, while number of partners, condom use, smoking, and ethnicity remained significant. In those aged 25 or over the total number of partners, ethnicity, and martial status were associated with infection. In white patients a history of one or more same sex partners was associated with a reduced risk of infection and significant associations were also seen for total number of partners, condom use, smoking, sex, and age. In black Caribbean patients drinking one to five units of alcohol per week was associated with a reduced risk of infection compared with non-drinkers, and the only other significant variable was age, demonstrating a reduced risk in those over 20.

\section{Discussion}

This large prospective study has demonstrated black Caribbean ethnicity to be an independent predictor of chlamydial infection in both men and women, and in those aged under 25 and 25 or over. This adds to earlier, retrospective studies conducted in Leeds ${ }^{20}$ and London ${ }^{21}$ showing an increased rate of gonorrhoea in black ethnic groups independent of socioeconomic status and a similar finding has also been reported for chlamydia from Coventry. ${ }^{19}$ One previous UK study, performed in a London STI clinic, has reported an increased risk of gonorrhoea and chlamydia in black men independent of both socioeconomic status and sexual behaviour. ${ }^{7}$ The present study also suggests that young adults (that is, teenagers) are the group most at risk from chlamydia and 
Table 4 Multivariate logistic regression analysis of variables associated with chlamydia infection - subanalysis by $\operatorname{sex}^{\star}$

\begin{tabular}{|c|c|c|}
\hline Variable & OR $(95 \%$ & $C I)$ \\
\hline \multicolumn{3}{|l|}{ Women $(\mathrm{n}=747)$} \\
\hline \multicolumn{3}{|l|}{ Occupational group } \\
\hline Homemaker & 1 & \\
\hline Student & 0.5 & $(0.3-1)$ \\
\hline Unemployed & 0.4 & $(0.2-0.9)$ \\
\hline Working & 0.4 & $(0.3-0.7)$ \\
\hline \multicolumn{3}{|l|}{ Age group } \\
\hline Under 20 & 1 & \\
\hline $20-24$ & 0.3 & $(0.2-0.5)$ \\
\hline $25-30$ & 0.3 & $(0.2-0.4)$ \\
\hline Over 30 & 0.1 & $(0.07-0.2)$ \\
\hline \multicolumn{3}{|c|}{ Total number of partners } \\
\hline 0 & 0.4 & $(0.03-4.9)$ \\
\hline 1 & 0.4 & $(0.3-0.6)$ \\
\hline 2 & 0.6 & $(0.4-0.9)$ \\
\hline Over 2 & 1 & \\
\hline \multicolumn{3}{|l|}{ Smoking } \\
\hline None & 12 & (1.4-98) \\
\hline $1-5 /$ day & 0.7 & $(0.5-1.04)$ \\
\hline Over $5 /$ day & 1 & \\
\hline \multicolumn{3}{|l|}{ Ethnic group } \\
\hline White & 1 & \\
\hline Black Caribbean & 1.9 & $(1.2-2.8)$ \\
\hline Other & 1.4 & $(0.9-2.4)$ \\
\hline \multicolumn{3}{|l|}{$\operatorname{Men}(n=624)$} \\
\hline \multicolumn{3}{|c|}{ Illicit drug use in past year } \\
\hline Yes & 1.5 & $(1.1-2.2)$ \\
\hline \multicolumn{3}{|c|}{ Total number of partners } \\
\hline 0 & 0.001 & (NS) \\
\hline 1 & 0.5 & $(0.3-0.8)$ \\
\hline 2 & 0.8 & $(0.5-1.2)$ \\
\hline Over 2 & 1 & \\
\hline \multicolumn{3}{|c|}{ Condom use with all partners } \\
\hline Never & 1 & \\
\hline Always & 0.4 & $(0.2-0.8)$ \\
\hline Sometimes/often & 0.9 & $(0.6-1.3)$ \\
\hline \multicolumn{3}{|l|}{ Smoking } \\
\hline None & 1180 & (NS) \\
\hline $1-5 /$ day & 0.8 & $(0.6-1.1)$ \\
\hline Over $5 /$ day & 1 & \\
\hline \multicolumn{3}{|l|}{ Ethnic group } \\
\hline White & 1 & \\
\hline Black Caribbean & 2 & $(1.4-3.1)$ \\
\hline Other & 1 & $(0.5-1.9)$ \\
\hline \multicolumn{3}{|l|}{ Marital status } \\
\hline Single & 3.4 & $(1.6-7.3)$ \\
\hline Married & 1 & \\
\hline Other† & 0.8 & $(0.2-3.1)$ \\
\hline
\end{tabular}

*Variables in the model: age, marital status, ethnic group, total number of partners, condom use with partners, history of gonorrhoea, history of foreign partner, number of same sex partners, alcohol, history of illicit drug use, occupational group, smoking, number of casual partners.

†Divorced, separated, living together, widowed.

confirms that these individuals are an important target for health education interventions to encourage behavioural change. The association between infection with increasing number of partners, decreased condom use, and being single are consistent with known risk behaviours for the acquisition of infection.

Infection was found to be associated with being male, despite the likelihood that infection in women results in a large asymptomatic reservoir. Since the population was selected from clinic attenders it would be unwise to extrapolate this finding to the general population however. Individuals who smoke may be thought of as being "risk takers" and an association with infection was indeed found in those who smoke more heavily. However, an increased risk was also seen in non-smokers which would not fit with this hypothesis. The confidence intervals for this finding were, however, very wide and need to be interpreted with caution.
Table 5 Multivariate logistic regression analysis of variables associated with chlamydia infection-subanalysis by age *

\begin{tabular}{|c|c|c|}
\hline \multirow{2}{*}{$\begin{array}{l}\text { Variable } \\
\text { Age under } 25(n=628)\end{array}$} & \multicolumn{2}{|c|}{$O R(95 \% C I)$} \\
\hline & & \\
\hline \multicolumn{3}{|c|}{ Total number of partners } \\
\hline 0 & 0.6 & $(0.05-7.4)$ \\
\hline 1 & 0.4 & $(0.3-0.6)$ \\
\hline 2 & 0.5 & $(0.3-0.8)$ \\
\hline Over 2 & 1 & \\
\hline \multicolumn{3}{|c|}{ Condom use with all partners } \\
\hline Never & 1 & \\
\hline Always & 0.3 & $(0.2-0.7)$ \\
\hline Sometimes/often & 0.7 & $(0.4-1.1)$ \\
\hline \multicolumn{3}{|l|}{ Smoking } \\
\hline None & 8 & $(1-65)$ \\
\hline $1-5 /$ day & 0.6 & $(0.4-0.9)$ \\
\hline Over $5 /$ day & 1 & \\
\hline \multicolumn{3}{|l|}{ Ethnic group } \\
\hline White & 1 & \\
\hline Black Caribbean & 2.3 & $(1.4-3.5)$ \\
\hline Other & 1.2 & $(0.7-2.1)$ \\
\hline \multicolumn{3}{|c|}{ Age 25 or over $(n=743)$} \\
\hline \multicolumn{3}{|c|}{ Total number of partners } \\
\hline 0 & \multicolumn{2}{|c|}{0.001 (NS) } \\
\hline 1 & 0.5 & $(0.3-0.8)$ \\
\hline 2 & 0.9 & $(0.6-1.4)$ \\
\hline Over 2 & 1 & \\
\hline \multicolumn{3}{|l|}{ Smoking } \\
\hline None & 1407 & (NS) \\
\hline $1-5 /$ day & 0.8 & $(0.6-1.1)$ \\
\hline Over $5 /$ day & 1 & \\
\hline \multicolumn{3}{|l|}{ Ethnic group } \\
\hline White & 1 & \\
\hline Black Caribbean & 1.9 & $(1.3-2.8)$ \\
\hline Other & 1.5 & $(0.9-2.7)$ \\
\hline \multicolumn{3}{|l|}{ Marital status } \\
\hline Single & 2.2 & $(1.2-4)$ \\
\hline Married & 1 & \\
\hline Other† & 0.8 & $(0.3-1.9)$ \\
\hline
\end{tabular}

*Variables in the model: sex, marital status, ethnic group, total number of partners, condom use with partners, history of gonorrhoea, history of foreign partner, number of same sex partners, alcohol, history of illicit drug use, occupational group, smoking, number of casual partners.

†Divorced, separated, living together, widowed.

Although performed prospectively the casecontrol design of this study has intrinsic limitations which may affect the interpretation of the results and their applicability to the general population. Both the cases and controls were taken from a sexually transmitted disease clinic population, representing a high risk group for infection. The control group may therefore have had a higher risk of unsafe sexual behaviour than the general population. It is however likely that this would reduce the difference between cases and controls, rather than falsely elevating it. The non-response rates are shown in table 2 and vary with individual questions. The non-responders were excluded from the multivariate analysis which raises the possibility of bias, particularly for those characteristics with high non-response rates-total number of partners, number of casual partners, condom use with all partners, condom use with casual partners, illicit drug use in the past year, and occupational group. The possibility of recall bias was reduced by ensuring that all participants completed the questionnaire before their consultation with the medical staff. It should also be recognised that the use of occupational class provides only a crude estimate of economic status and raises the possibility of identifying additional associations if a more discriminating classification was used. 
Table 6 Multivariate logistic regression analysis of variables associated with chlamydia infection - subanalysis by ethnicity*

\begin{tabular}{|c|c|}
\hline Variable & OR $(95 \% C I)$ \\
\hline \multicolumn{2}{|c|}{ White $(n=913)$} \\
\hline \multicolumn{2}{|c|}{ Total number of partners } \\
\hline 0 & $0.3(0.03-3.3)$ \\
\hline 1 & $0.4(0.3-0.6)$ \\
\hline 2 & $0.6(0.4-0.9)$ \\
\hline Over 2 & 1 \\
\hline \multicolumn{2}{|c|}{ No of same sex partners } \\
\hline 1 or more & $0.2(0.04-0.8)$ \\
\hline \multicolumn{2}{|c|}{ Condom use with all partners } \\
\hline Never & 1 \\
\hline Always & $0.5(0.3-0.8)$ \\
\hline Sometimes/often & $0.7(0.5-0.9)$ \\
\hline \multicolumn{2}{|l|}{ Smoking } \\
\hline None & $11 \quad(1.3-91)$ \\
\hline $1-5 /$ day & $0.6(0.5-0.8)$ \\
\hline Over $5 /$ day & 1 \\
\hline \multicolumn{2}{|l|}{ Sex } \\
\hline Male & $1.4(1.03-1.9)$ \\
\hline \multicolumn{2}{|l|}{ Age group } \\
\hline Under 20 & 1 \\
\hline $20-24$ & $0.4(0.2-0.6)$ \\
\hline $25-30$ & $0.3(0.2-0.5)$ \\
\hline Over 30 & $0.2(0.1-0.3)$ \\
\hline \multicolumn{2}{|c|}{ Black Caribbean $(n=316)$} \\
\hline \multicolumn{2}{|c|}{ No of same sex partners } \\
\hline 1 or more & 2047 (NS) \\
\hline \multicolumn{2}{|l|}{ Smoking } \\
\hline None & 1477 (NS) \\
\hline $1-5 /$ day & $1.1(0.6-1.9)$ \\
\hline Over $5 /$ day & 1 \\
\hline \multicolumn{2}{|l|}{ Alcohol } \\
\hline None & 1 \\
\hline $1-5$ units/week & $0.4(0.2-0.8)$ \\
\hline$>5$ units/week & $0.5(0.2-1.1)$ \\
\hline \multicolumn{2}{|l|}{ Age group } \\
\hline Under 20 & 1 \\
\hline $20-24$ & $0.4(0.2-0.8)$ \\
\hline $25-30$ & $0.4(0.2-0.8)$ \\
\hline Over 30 & $0.2(0.1-0.4)$ \\
\hline
\end{tabular}

*Variables in the model: sex, age, marital status, total number of partners, condom use with partners, history of gonorrhoea, history of foreign partner, number of same sex partners, alcohol, history of illicit drug use, occupational group, smoking, number of casual partners.

†Divorced, separated, living together, widowed.

Alternative factors, such as differences in sexual mixing patterns or in the effectiveness of healthcare interventions (for example, partner notification and follow up), need to be explored to seek an explanation for these findings.

Unmarried status was found to be an independent risk factor on multivariate analysis. To our knowledge this is an original finding - smaller controlled studies from the United Kingdom, ${ }^{6}$ United States, ${ }^{9}$ Sweden, ${ }^{14}$ and Australia ${ }^{22}$ failed to find this association.

The only association found with socioeconomic status, as measured by the nature of employment, was in women who were at increased risk of infection when they were "homemakers." The reason for this is not clear although other studies have also found little association with socioeconomic status. ${ }^{1423-26}$ However, it should be noted that in this present study a relatively imprecise measure of socioeconomic status in the form of employment was utilised. Illicit drug misuse was found to be associated with an increased risk of chlamydial infection in men. This may reflect an increased predisposition to risk taking behaviour and also raises the possibility of increased high risk behaviour while under the influence of illicit drugs. The risk factors for chlamydial infection for those aged under and over 25 were similar although condom use was only significant for the younger patients and marital status for those aged over 25 . In black Caribbean patients the only factors significantly associated with chlamydia were age under 20 and being teetotal. This was however the smallest subgroup analysis $(n=316)$, raising the possibility that a large study population with greater power may identify more significant variables.

In relation to sexual behaviour and in agreement with previous research, this study shows that an increasing number of sexual partners is a risk factor for infection but that homosexuality and consistent condom use are protective. Perhaps counterintuitively, an increased number of casual sexual partners (defined as people with whom there was a single sexual encounter) did not increase the risk of being infected. This finding has been previously reported in a study conducted in a London STI clinic. ${ }^{8}$ Although overall consumption of alcohol did not correlate with chlamydial infection, use of illicit drugs did. To our knowledge this association has not previously been demonstrated.

The results of this research have implications for sexual health promotion activities. Information concerning chlamydia and its prevention should be targeted to those most at risknamely, young, unmarried heterosexuals and people of black Caribbean ethnicity. Health education messages should stress that risk of infection rises with increasing number of sexual partners and should seek to dispel the widely held view that casual partners are the source of greatest risk. The sobering finding that $44 \%$ of cases and $30 \%$ of controls in this study admitted to using illicit drugs in the previous 12 months shows clearly that health education aimed at STI clinic attendees should address this issue as well as the prevention of infection.

1 Stamm WE. Chlamydia trachomatis infections of the adult. In: Holmes KK, Mardh P-A, Sparling PF, et al, eds. SexuIn: Holmes KK, Mardh P-A, Sparling PF, et al, eds. Sexu-
ally transmitted diseases. 3rd ed. New York: McGraw-Hill, ally transmitted

2 Simms I, Catchpole M, Brugha R, et al. Epidemiology of genital Chlamydia trachomatis in England and Wales. Genitourin Med 1997;73:122-6.

3 Matondo P, Wall R, Morgan K, et al. Epidemiology of gonococcal and chlamydial infections in Harrow and Brent. Genitourin Med 1996;72:352-7.

4 Oakeshott P, Kerry S, Hay S, et al. Opportunistic screening for chlamydial infection at time of cervical smear testing in general practice: prevalence study. BMF 1998;316:351-2.

5 Evans BA, Tasker T, MacRae KD. Risk profiles for genital infection in women. Genitourin Med 1993;69:257-61.

6 Grun L, Tassano-Smith J, Carder C, et al. Comparison of two methods of screening for genital chlamydial infection in women attending in general practice: cross sectional survey. $B M \mathcal{F}$ 1997;315:226-30.

7 Evans BA, Bond RA, MacRae KD. Racial origin, sexual behaviour, and genital infection among heterosexual men ttending a genitourinary medicine clinic in London 1993-4). Sex Transm Inf 1998;74:40-4.

8 Evans BA, Kell PD, Bond RA, et al. Heterosexual relationships and condom-use in the spread of sexually transmitted diseases to women. Genitourin Med 1995;71: $291-4$.

9 Handsfield HH, Jasman LL, Roberts PL, et al. Criteria for selective screening for Chlamydia trachomatis infection in women attending family planning clinics. $\mathcal{F} A M A 1986 ; 255$ : 1730-4.

10 Hart G. Risk profiles and epidemiologic interrelationships of sexually transmitted diseases. Sex Transm Dis 1993;20: 126-36.

11 Van Duynhoven YTHP, van de Laar MJW, Schop WA, et al. Different demographical and sexual correlates for chlamydial infection and gonorrhoea. Int $\mathcal{f}$ Epidemiol 1997;26: dial infection

12 Vincelette J, Baril JG, Allard A. Predictors of chlamydial infection and gonorrhoea among patients seen by private practitioners. Can Med Assoc f 1991;144:713-21. 
13 Edlin BR, Irwin KL, Farque S, et al. Intersecting epidemicscrack cocaine use and HIV infection among inner-city young adults. N Engl $f$ Med 1994;331:1422-7.

14 Jonsson M, Karlsson R, Persson K, et al. The influence of sexual and social factors on the risk of Chlamydia trachomatis infections: a population-based serologic study. Sex Transm Dis 1995;22:355-63.

15 Bjekic M, Vlajinac H, Sipetic S, et al. Risk factors for gonorrhoea: case-control study. Genitourin Med 1997;73 518-21.

16 Shafer M-A, Hilton JF, Ekstrand M, et al. Relationship between drug use and sexual behaviors and the occurrence of sexually transmitted diseases among high-risk male youth. Sex Transm Dis 1993;20:307-13.

17 Sherrard J, Barlow D. Men with repeated episodes of gonorrhoea 1990-1992. Int $\mathcal{F}$ STD AIDS 1996;7:281-3.

18 Schwarz SK, Bolan GA, Fullilove M, et al. Crack cocaine and the exchange of sex for money or drugs: risk factors for gonorrhoea among black adolescents in San Francisco. Sex Transm Dis 1992;19:7-13.

19 Winter AJ, Sriskandabalan P, Wade AAH, et al. Sociodemography of genital Chlamydia trachomatis in Coventry, UK,

20 Lacey CJN, Merrick DW, Bensley DC, et al. Analysis of the sociodemography of gonorrhoea in Leeds, 1989-93 [see comments]. BMF 1997;314:1715-18

21 Low N, Daker-White G, Barlow D, et al. Gonorrhoea in inner London: results of a cross-sectional study. BMF 1997;314:1719-23.

22 Hart G. Factors associated with genital chlamydial and gonococcal infections in females. Genitourin Med 1992;68: $217-20$.

23 Ellen JM, Kohn RP, Bolan GA, et al. Socioeconomic differences in sexually transmitted disease rates among black and white adolescents, San Francisco, 1990 to 1992. Am f Pubwhite adolescents, San Francis
lic Health 1995;85:1546-8.

24 McCormack WM, Rosner B, McComb E, et al. Infection with Chlamydia trachomatis in female college students. $\mathrm{Am}$ $\mathcal{f}$ Epidemiol 1985;121:107-15.

25 Jolly AM, Orr PH, Hammond G, et al. Risk factors for infection in women undergoing testing for Chlamydia trachomatis and Neisseria gonorrhoeae in Manitoba, Canada. Sex Transm Dis 1995;22:289-95.

26 Ramstedt K, Forssman L, Giesecke J, et al. Risk factors for Chlamydia trachomatis infection in 6810 young women attending family planning clinics. Int $\mathcal{F}$ STD AIDS 1992;3: $117-22$. 